OPEN ACCESS

Edited by:

Russell T. Hill,

University of Maryland Center

for Environmental Science, USA

Reviewed by:

Julie L. Meyer,

University of Florida, USA

Jose V. Lopez,

Nova Southeastern University, USA

*Correspondence:

Pierre E. Galand

pierre.galand@obs-banyuls.fr

Specialty section:

This article was submitted to

Microbial Symbioses,

a section of the journal

Frontiers in Microbiology

Received: 26 November 2015

Accepted: 03 May 2016

Published: 19 May 2016

Citation:

Blanquer A, Uriz MJ, Cebrian E and Galand PE (2016) Snapshot of a Bacterial Microbiome Shift during the Early Symptoms of a Massive

Sponge Die-Off in the Western

Mediterranean.

Front. Microbiol. 7:752

doi: 10.3389/fmicb.2016.00752

\section{Snapshot of a Bacterial Microbiome Shift during the Early Symptoms of a Massive Sponge Die-Off in the Western Mediterranean}

\author{
Andrea Blanquer ${ }^{1}$, Maria J. Uriz ${ }^{1}$, Emma Cebrian ${ }^{1,2}$ and Pierre E. Galand ${ }^{3 *}$ \\ ${ }^{1}$ Centre d'Estudis Avançats de Blanes, Consejo Superior de Investigaciones Cientificas, Girona, Spain, ${ }^{2}$ Departament de \\ Ciències Ambientals, Facultat de Ciències, Universitat de Girona, Girona, Spain, ${ }^{3}$ Laboratoire d'Ecogéochimie des \\ Environnements Benthiques, Observatoire Océanologique de Banyuls, Sorbonne Universités, Université Pierre et Marie \\ Curie, Université Paris 06, Centre National de la Recherche Scientifique, Paris, France
}

Ocean warming is affecting marine benthic ecosystems through mass mortality events that involve marine invertebrates, in particular bivalves, corals, and sponges. Among these events, extensive die-offs of Ircinia fasciculata sponges have been recurrently reported in western Mediterranean. The goal of our study was to test whether the temperature-related mass sponge die-offs were associated with or preceded by an early unbalanced bacterial microbiome in the sponge tissues. We took advantage of the early detection of disease and compared the microbiomes of healthy vs. early diseased I. fasciculata tissues. Our results showed a microbiome shift in early diseased tissues. The abundance of Gammaproteobacteria and Acidobacteria increased and that of Deltaproteobacteria decreased in diseased vs. healthy tissues. The change in community composition was also noticeable at the operational taxonomic unit (OTU) level. Diseased tissues contained more bacterial sequences previously identified in injured or stressed sponges and corals than healthy tissues. Bacterial diversity increased significantly in diseased tissues, which contained a higher number of low abundance OTUs. Our results do not support the hypothesis of one particular pathogen, whether a Vibrio or any other bacteria, triggering the Northwestern Mediterranean mass mortalities of I. fasciculata. Our data rather suggest an early disruption of the bacterial microbiome balance in healthy sponges through a shift in OTU abundances, and the purported consequent decline of the sponge fitness and resistance to infections. Opportunistic bacteria could colonize the sponge tissues, taking benefit of the sponge weakness, before one or more virulent pathogens might proliferate ending in the mass sponge die-off.

Keywords: mass die-off, keratose sponges, early disease symptoms, microbiome profiling, microbiome shifts, bacterial symbionts, Ircinia fasciculata, western Mediterranean

\section{INTRODUCTION}

Ocean warming is affecting marine benthic ecosystems through epidemiologic diseases and mass mortalities of invertebrates, in particular bivalves, corals and sponges (Harvell et al., 2002). The mass mortality events are increasing across all oceans (Webster, 2007) and may lead to declines, or rises of other benthic species, with unpredictable subsequent effects (Pinnegar et al., 2000). 
Moreover, mass mortalities not only alter benthic assemblages but also may impair species harvesting and sea cultures with biotechnological purposes (Schippers et al., 2012).

The etiological agents responsible for marine mass mortalities have rarely been unambiguously identified (e.g., Angermeier et al., 2011, 2012). In corals, where diseases have long been studied (e.g., Rosenberg and Ben-Haim, 2002; Sutherland et al., 2004), the growing theory is that diseases are caused by opportunistic polymicrobial infections, rather than by a single primary pathogen (Lesser et al., 2007; Bourne et al., 2008; Rosenberg et al., 2009). Diseases usually follow an environmental perturbation (e.g., anomalous high temperatures) that produces physiological stress to the holobiont, which may unbalance the associated microbial community. Indeed, it has been proposed that coral diseases are caused by a change of some benign components of the associated microbial communities into pathogens (Lesser et al., 2007).

In sponges, several causative agents of the diseases have been proposed (Webster et al., 2002; Cervino et al., 2006; Webster, 2007; Luter et al., 2010; Stabili et al., 2012) but seldom unambiguously confirmed (Choudhury et al., 2015). Microorganisms involved in sponge diseases may be: (i) symbionts that turn into pathogens, often by increasing their abundance (i. e., Rützler, 1988; Olson et al., 2006, 2014); (ii) symbionts that change their virulence (but not necessarily their abundance) because of environmental changes (i.e., Smith, 1941); (iii) external microorganisms that interact with and modify the sponge symbiotic community (i.e., Webster et al., 2008); (iv) external common pathogens; (v) several combinations of the above-mentioned factors. Moreover, environmental factors can simply modify the composition of the symbiotic community (Lemoine et al., 2007; López-Legentil et al., 2008, 2010; Webster et al., 2008; Gao et al., 2015), which may reduce the host fitness and thus its resistance to external pathogenic microbes (Saby et al., 2009).

In the Mediterranean, mass mortality events, positively correlated with anomalously high seawater temperatures, have affected benthic filter-feeders and suspension-feeders recurrently (e.g., Cerrano et al., 2000; Perez et al., 2000; Coma et al., 2006; Garrabou et al., 2009). The most disturbed organisms have been gorgonians and sponges with proteinaceous skeletons (Perez et al., 2000; Garrabou et al., 2009), in particular representatives of Family Irciniidae (Maldonado et al., 2010; Cebrian et al., 2011; Stabili et al., 2012). Ircinia fasciculata (Pallas, 1766) is one of the most abundant Ircinidae in the shallow sublittoral, where it can reach large sizes and provide shading refuge for many benthic invertebrates including polychaetes, crustaceans, sipunculids, and small fishes (Koukouras et al., 1985, 1992). I. fasciculata belongs to the so-called bacteriosponges (i.e., High Microbial Abundance-HMA-sponges) (Blanquer et al., 2013), and harbors both phototrophic and heterotrophic bacteria. The former are mainly composed of one Cyanobacteria species densely distributed at the sponge periphery (Turon et al., 2013).

Extensive die-offs of Ircinia populations were reported during the 2008, 2009, and 2010 summers in the western Mediterranean (Maldonado et al., 2010; Cebrian et al., 2011), south Adriatic and Ionian Seas (Stabili et al., 2012), and North Adriatic (Di
Camillo et al., 2013). The 2009 mortality represented one of the most severe sponge disease reported up to now as it affected up to $95 \%$ of the individuals of $I$. fasciculata from several marine protected areas of the western Mediterranean, with up to $100 \%$ of the individuals injured (Cebrian et al., 2011).

There are two main running hypotheses on the disease origin in Mediterranean Ircinia species based on indirect evidence. Some authors suggest that a twisted rod bacterium was involved in the disease, because of its presence in ultrastructure sections of diseased sponges (Maldonado et al., 2010). Other authors consider the bacterium Vibrio rotiferianus as a primary disease agent because it represented a higher proportion of bacteria in cultures from diseased individuals compared to healthy specimens (Stabili et al., 2012). However, none of these studies could refute that the putative etiological agents were not just opportunistic microbes that proliferated in stressed, damaged or dead sponge tissues (Gaino and Pronzato, 1989; Vacelet et al., 1994). Other authors tested experimentally the effect of higher temperatures on the physiology of the symbiotic cyanobacteria of I. fasciculata, and found that the sea temperatures recorded during mortality events strongly altered the cyanobacteria physiology (Cebrian et al., 2011). This study pointed to Cyanobacteria community shifts as a purported factor prompting the disease, since physiological alterations of Cyanobacteria occurred before the first external symptoms were detected (Cebrian et al., 2011).

Recent studies have emphasized the stability of the I. fasciculata associated bacteria through spatial and temporal scales (Erwin et al., 2012b; Pita et al., 2013a,b), and at high temperatures, but below the threshold producing sponge mortalities (Pita et al., 2013a). The sponge microbiome stability under sublethal thermal stress has also been reported for Rhopaloeides odorabile (Simister et al., 2012). Microbiome stability under changing conditions highlights the strength of these multiple symbioses and suggests that changes in the sponge microbiome may be a good proxy of sponge fitness decay and an indicator of a possible forthcoming sponge disease.

The main objective of this study was to test the hypothesis that sponge disease may be initiated by an unbalance in the sponge bacterial communities. We took advantage of the early detection of disease and compared the microbiome profiling of healthy and early diseased I. fasciculata tissues before opportunistic pathogens could have arrived. This is the first time that microbiomes from a mass mortality event of the sponge I. fasciculata have been captured before the disease symptoms were widely manifested.

\section{MATERIALS AND METHODS}

\section{Sampling}

Three I. fasciculata sponges showing signs of disease were sampled during the 2010 summer disease episode from the Scandola Marine Protected Area (Corsica, France). All the sampled sponges later died. For each sponge, samples were collected from healthy tissues and from the area in close contact with small white spots. Sponge samples were put in 
individual tanks underwater and kept in the receptacles until fixed in absolute ethanol once on surface. Three replicates of 1.51 seawater samples were also sampled from the vicinity of the sponges and filtered through three distinct $0.2 \mu \mathrm{m}$ sterile filers (GE Osmonics, Minnetonka, MN, USA). The filters were maintained frozen at $-80^{\circ} \mathrm{C}$ until DNA extraction.

Healthy I. fasciculata have a dense external layer of the Cyanobacteria Candidatus Synechococcus spongiarum (Erwin et al., 2012c), which confers a characteristic yellowish to violet color to the sponge surface (Figure 1). We defined early diseased tissues the areas close to diseased tissues that show a lighter violet color. Conspicuously diseased tissues lacked the Cyanobacteria layer as confirmed by their whitish color but maintained their ectosome intact (Figure 1). To avoid a single Cyanobacteria operational taxonomic unit (OTU) flooding our bacterial dataset, the external layer of the sponge samples was removed before DNA extraction.

\section{DNA Extraction, PCR, and Sequencing}

DNA from sponges was extracted with DNeasy blood and tissue kit (Qiagen; Blanquer et al., 2013). DNA concentration and quality were assessed using Qubit fluorometer (Invitrogen) and a Biomate spectrophotometer (Thermo Scientific), respectively. Extractions were performed on the inner sponge tissue to avoid the external Cyanobacteria-rich layer. As mentioned above, the aim was to prevent an overrepresentation of Cyanobacteria species, which would have decreased considerably the coverage of the heterotrophic bacterial communities. Bacterial 16S rRNA genes were amplified using primers 28F TTTGATCNTGGCTCAG and 519R GTNTTACNGCGGCKGCTG with a single-step 28 cycles PCR using the Hot Star Taq Plus Master Mix Kit (Qiagen). The PCR conditions were: $94^{\circ} \mathrm{C}$ for $3 \mathrm{~min}$, followed by 28 cycles of $94^{\circ} \mathrm{C}$ for $30 \mathrm{~s}, 53^{\circ} \mathrm{C}$ for $40 \mathrm{~s}$, and $72^{\circ} \mathrm{C}$ for $1 \mathrm{~min}$, after which a final elongation step at $72^{\circ} \mathrm{C}$ for $5 \mathrm{~min}$ was performed. Following PCR, all amplicon products from the different samples were mixed in equal concentrations and purified using Agencourt Ampure beads (Agencourt Bioscience
Corporation). Pyrosequencing was done with a Roche 454 FLX using commercially prepared Titanium reagents by a commercial laboratory (Research and Testing Laboratory, Lubbock, TX, USA). Sequences were deposited in NCBI SRA under BioProject PRJNA315365.

\section{Sequence Data Analyses}

First, sequences were quality controlled by removing all reads that had a mismatch with the $16 \mathrm{~S}$ rRNA primers, contained ambiguous nucleotides (N) and that were $<270$ nucleotides long after the forward primer. Then, a stringent quality trimming criteria was applied to remove reads having $\geq 3 \%$ of bases with Phred values $<27$ ( $0.2 \%$ per-base error probability). This is recommended to minimize erroneous reads when clustering at 97\% (Huse et al., 2010; Kunin et al., 2010). Sequences were then de-replicated and clustered at a 97\% threshold using Uclust (Edgar, 2010). Sequences from each OTU were classified by comparison to the Greengenes database (DeSantis et al., 2006). Sequence data analyses were conducted with Pyrotagger (Kunin and Hugenholtz, 2010). The taxonomic affiliations of the most abundant OTUs ( $>1 \%$ of the sequences) were further verified against sequences from the NCBI databases using BLAST (Altschul et al., 1990).

To compare bacterial communities for diversity analysis, all samples were randomly resampled to the size of the sample containing fewest sequences $(n=958)$ using Daisy Chopper (Gilbert et al., 2009). The Shannon diversity index $\left(H^{\prime}\right)$, the dominance index $(D)$ and cluster analysis based on Bray-Curtis similarity were conducted using the software PAST (Hammer et al., 2001). Statistic comparisons of $H^{\prime}$ and $D$ between healthy and diseased sponge tissues were performed by Wilcoxon pairtest.

We also used PAST to conduct an analysis of similarities (ANOSIMs) using the Bray-Curtis distance to test if there were differences in community composition between groups of samples (Clarke et al., 2006).

A phylogenetic tree was constructed from the abundant OTUs and OTUs that showed significant changes in abundance
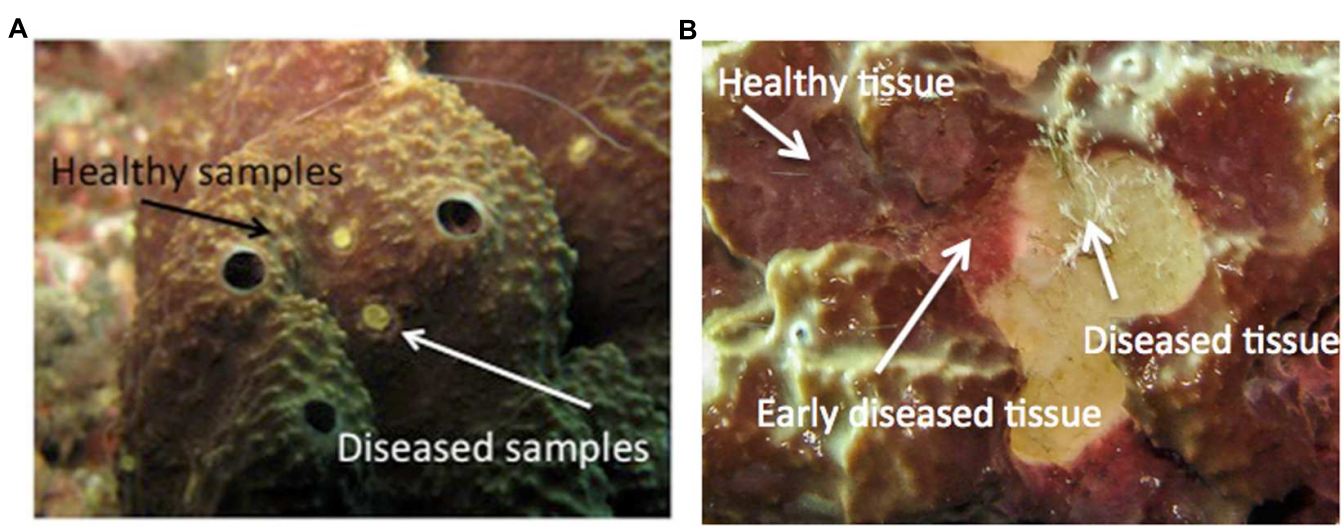

FIGURE 1 | Details of Ircinia fasciculata sponges at different stages of the disease. (A) Early diseased individual (arrows indicate the tissue sampled). (B) An advanced disease stage (arrows point to healthy, what we consider early diseased, and advanced diseased tissues). 
between healthy and diseased tissues. Representative sequences for each OTU together with their best match from GenBank were aligned using MUSCLE (Edgar, 2004), and phylogenetic analyses were completed with the program PHYLIP (Felsenstein, 1989). DNADIST was used to calculate genetic distances using Kimura2 model. The distance tree was estimated with the phylogenetic algorithm FITCH in the PHYLIP program. The significance of changes in phylum/class and OTU abundance was tested with a $t$-test and figures constructed with STAMP (Parks et al., 2014).

\section{RESULTS}

\section{Alpha and Beta Diversity}

A total of 16144 raw reads of the 16S rRNA gene were obtained from the sponge samples, and 16642 row reads from the surrounding seawater. After removing poor-quality reads, a total of 12842 reads remained (7532from sponge samples and 5310 from seawater). The total number of OTUs at a sequence similarity of $97 \%$ was 305 for the sponge tissues and 368 for the water.

The Shannon diversity index $\left(H^{\prime}\right)$ calculated from the resampled dataset was significantly higher (Wilcoxon pair-test, $p<0.05)$ in diseased samples compared to healthy samples (3.40 vs. 2.93 in average, respectively; Table 1). Conversely, the Simpson's $D$ was significantly higher (Wilcoxon pair test, $p<0.05)$ in healthy than in diseased tissues $(0.10$ and 0.07 in average, respectively; Table 1). Seawater samples had a higher number of OTUs than sponge tissues, whether healthy or diseased (Table 1), but significantly lower Shannon diversity than both types of sponge samples (Wilcoxon pair-test, $p<0.01$ for both comparisons). Conversely the Simpson's dominance index was significantly higher (Student $t$-test, $p<0.001$ ) for seawater samples $(D=0.3$ in average) than for sponges.

Cluster analysis of the samples (healthy and diseased sponges and water) based on their respective microbial community composition, using the Bray-Curtis similarity index, showed that the healthy tissues clustered together, apart from the

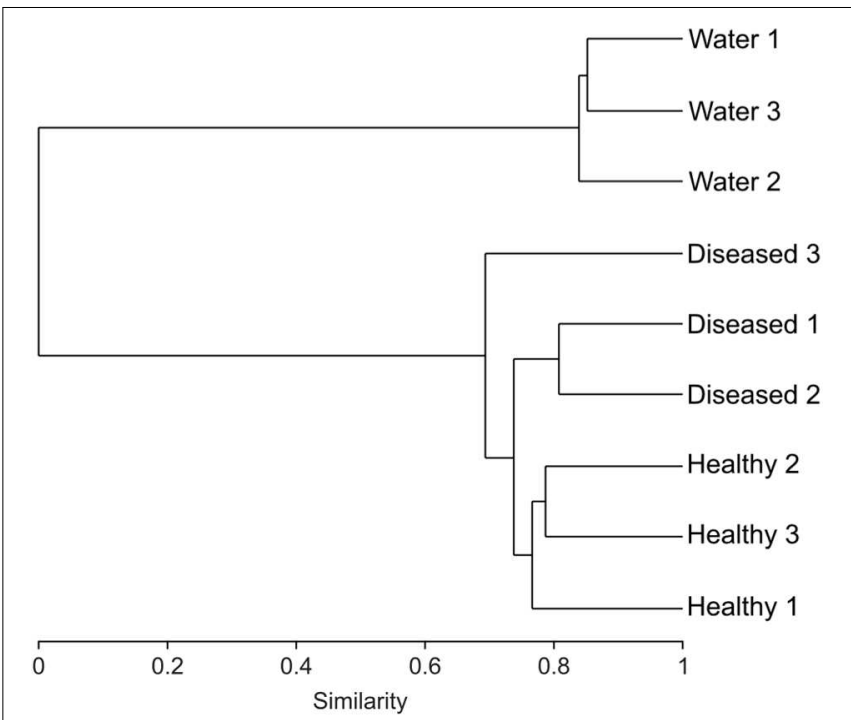

FIGURE 2 | Dendrogram based on the Bray-Curtis index showing the similarity between the 16S rRNA bacterial community for three diseased, healthy and surrounding seawater samples.

diseased tissues (ANOSIM, $R=0.65$; Figure 2), although one of the replicated samples of diseased tissue appeared as a sister group of both healthy and diseased. This replicate differed from the other two diseased samples by a lower number of Verrucomicrobia OTUs and the presence of Nitrospirae (Figure 3). The bacterial communities from the sponge tissues, either healthy or diseased, separated from that of seawater (ANOSIM, $R=1$; Figure 2).

\section{Bacteria Community Composition in Sponges (Healthy and Diseased Tissues)}

\section{vs. Seawater}

Seawater samples were dominated by Proteobacteria, especially from the class Alphaproteobacteria (89\% of the sequences; Figure 3), which belonged mainly to the SAR11 clade.

TABLE 1 | Number of sequences, operational taxonomic units (OTUs), and diversity and dominance indices of bacterial communities from healthy and diseased sponge tissues, and surrounding seawater.

\begin{tabular}{|c|c|c|c|c|c|c|c|c|}
\hline & \multicolumn{4}{|c|}{ All } & \multicolumn{4}{|c|}{ Resampled } \\
\hline & Sequences & OTUs & $H^{\prime}$ & $D$ & Sequences & OTUs & $H^{\prime}$ & $D$ \\
\hline Healthy 1 & 1381 & 93 & 2.9 & 0.10 & 915 & 71 & 2.8 & 0.10 \\
\hline Healthy 2 & 1107 & 91 & 2.9 & 0.11 & 915 & 70 & 2.8 & 0.11 \\
\hline Healthy 3 & 1542 & 104 & 3.0 & 0.10 & 915 & 77 & 2.9 & 0.11 \\
\hline Diseased 1 & 1215 & 97 & 3.3 & 0.07 & 915 & 73 & 3.2 & 0.07 \\
\hline Diseased 2 & 1372 & 130 & 3.4 & 0.06 & 915 & 104 & 3.4 & 0.06 \\
\hline Diseased 3 & 915 & 119 & 3.4 & 0.07 & 915 & 119 & 3.4 & 0.07 \\
\hline Water 1 & 2433 & 223 & 2.5 & 0.32 & 915 & 107 & 2.4 & 0.31 \\
\hline Water 2 & 1849 & 196 & 2.6 & 0.31 & 915 & 113 & 2.39 & 0.32 \\
\hline Water 3 & 1028 & 148 & 2.6 & 0.27 & 915 & 104 & 2.4 & 0.31 \\
\hline
\end{tabular}

$H^{\prime}$, Shannon index; D, Dominance. 


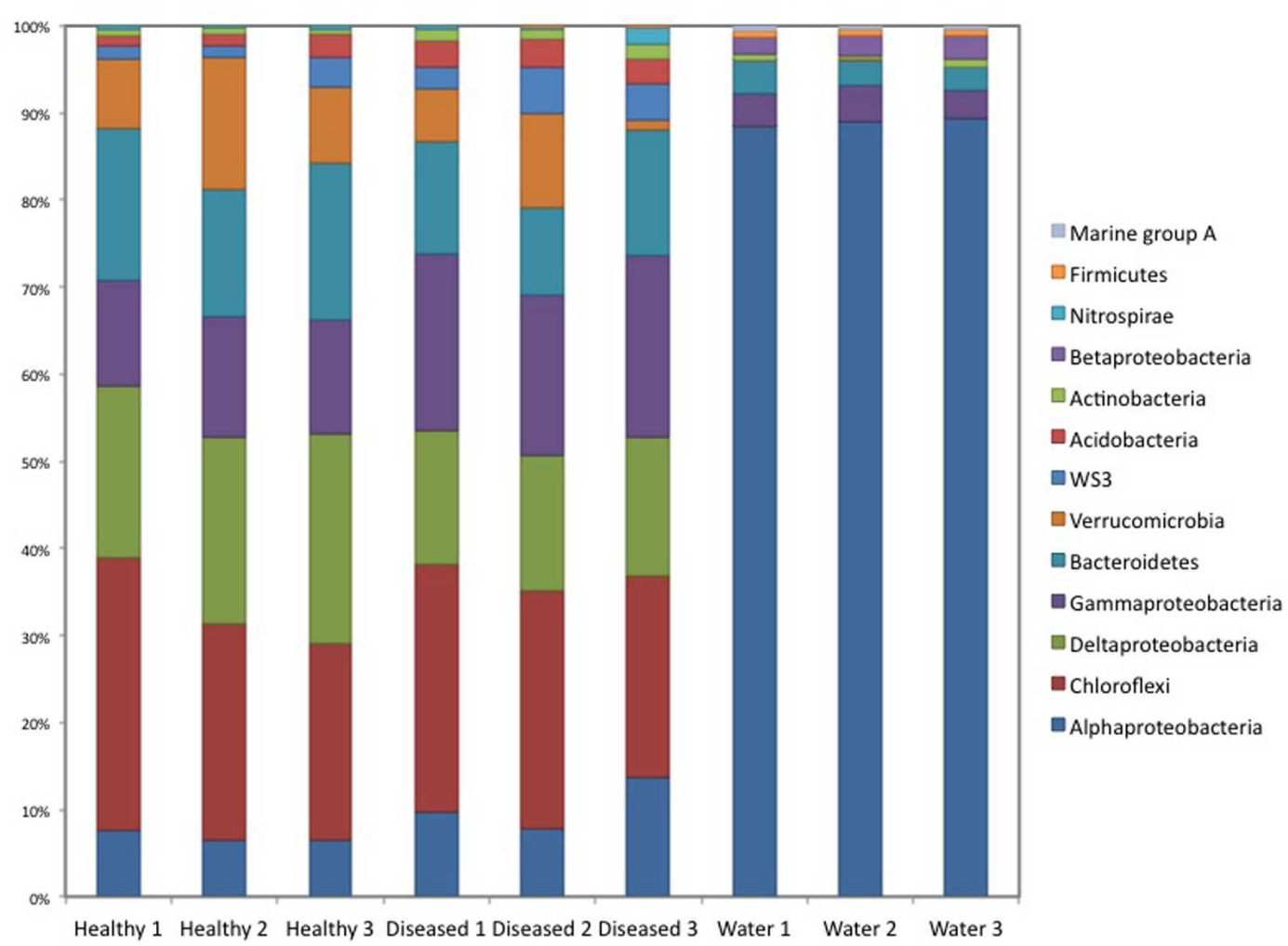

FIGURE 3 | Bacterial community composition for diseased and healthy sponge tissues, and the surrounding water.

Bacteroidetes was the second most abundant phylum in seawater samples. Sponge samples were also dominated by Proteobacteria but in this case mainly belonging to Deltaproteobacteria and Gammaproteobacteria. Chloroflexi, Bacteroidetes, and Verrucomicrobia were also abundant in sponge tissues (Figure 3). All abundant sponge sequences were similar to sequences known from the genus Ircinia or from other marine sponges belonging to several Porifera orders (e.g., Aplysina aerophoba, Xestospongia testudinaria, and Haliclona hogarthi). The most common Deltaproteobacteria (Ifas_40), Chloroflexi (Ifas_36), Bacteroidetes (Ifas_42)and Alphaproteobacteria (Ifas_287) were identical to sequences from Ircinia species (Erwin et al., 2012a,b) (Figure 4), while the abundant Verrucomicrobia (Ifas_32) was similar to sequences from $X$. testudinaria (Montalvo and Hill, 2011).

\section{Healthy vs. Diseased Sponge Tissues}

There were no qualitative differences between healthy and diseased tissues among the dominant groups at high taxonomical levels (phylum or class). However, a significant shift in abundance was detected for some groups. Gammaproteobacteria, Acidobacteria, and Actinobacteria increased in diseased tissues while Deltaproteobacteria were more abundant in healthy tissues (Figure 3). Changes were also detected at the OTU level (Figure 5). Among Gammaproteobacteria (Figure 4), OTUs Ifas_94 and Ifas_128 increased significantly in abundance in diseased tissues. Among Deltaproteobacteria, the OTU Ifas_40 (Figure 4) decreased in abundance in diseased tissues (Figure 5).
Qualitative differences between healthy and diseased sponges became relevant at lower taxonomical levels. More than $40 \%$ of the OTUs retrieved from healthy samples exclusively and 20\% only found in the diseased samples had already been reported for the genus Ircinia. Furthermore, $8.6 \%$ of the bacteria only found in the diseased samples had already been associated to coral or sponge diseases, $2.6 \%$ to cultured sponges, and $2.6 \%$ to polluted environments (i.e., contaminated sediments or waste waters; Figure 6).

Further, there was a higher proportion of abundant OTUs in healthy tissues while in diseased tissues less abundant OTUs predominated (Figure 7). More specifically, several OTUs significantly decreased in abundance in diseased samples. It was the case for the sponge most abundant OTU (Ifas_40) but also for other less abundant OTUs (Figure 7).

Vibrio sequences were rare. One Vibrio OTU (Ifas_224) was detected and was present only in the diseased samples (two sequences). It was $100 \%$ similar to Vibrio sequences found earlier in both healthy and diseased sponge and coral species.

As for the phototrophic bacteria, a total of 23 Cyanobacteria OTUs were retrieved from both healthy and diseased Ircinia (remember that the Candidatus Synechococcus spongiarum layer was removed). The most abundant Cyanobacteria OTU (Ifas_228) was similar to sequences previously found in Ircinia (AF10-97_C30, Erwin et al., 2012b). This OTU, which was not detected in the water, was significantly more abundant in healthy than in diseased tissue. 

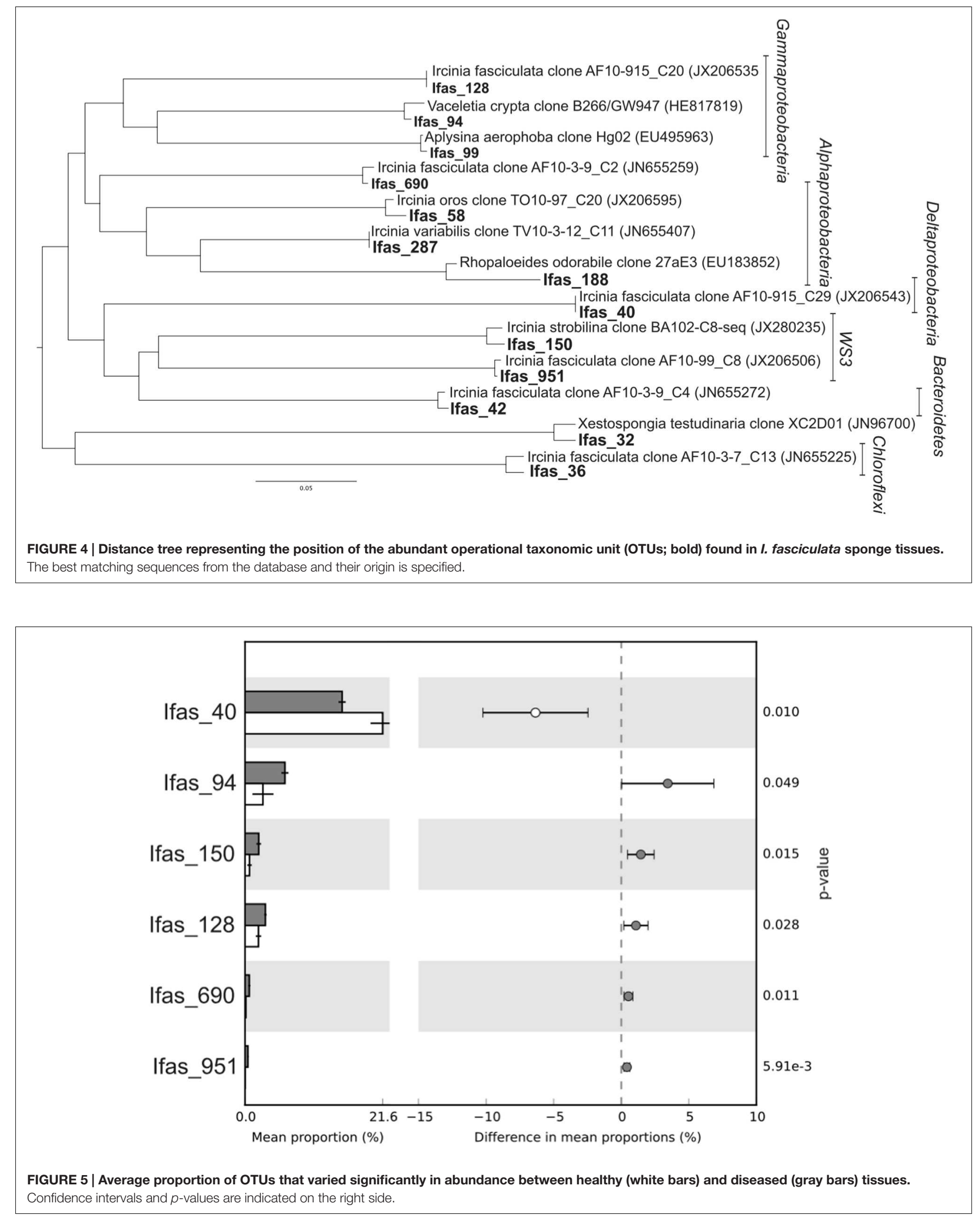


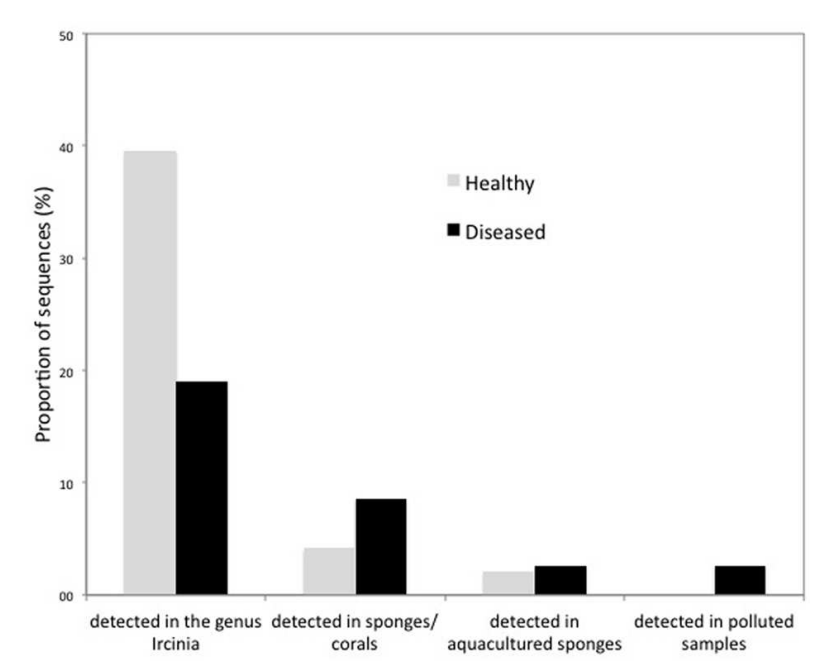

FIGURE 6 | Percentages of OTUs only recovered from healthy and diseased tissues of $I$. fasciculata that were previously described from the Ircinia genus, from diseased sponges or corals, from aquacultured sponges or from polluted samples.

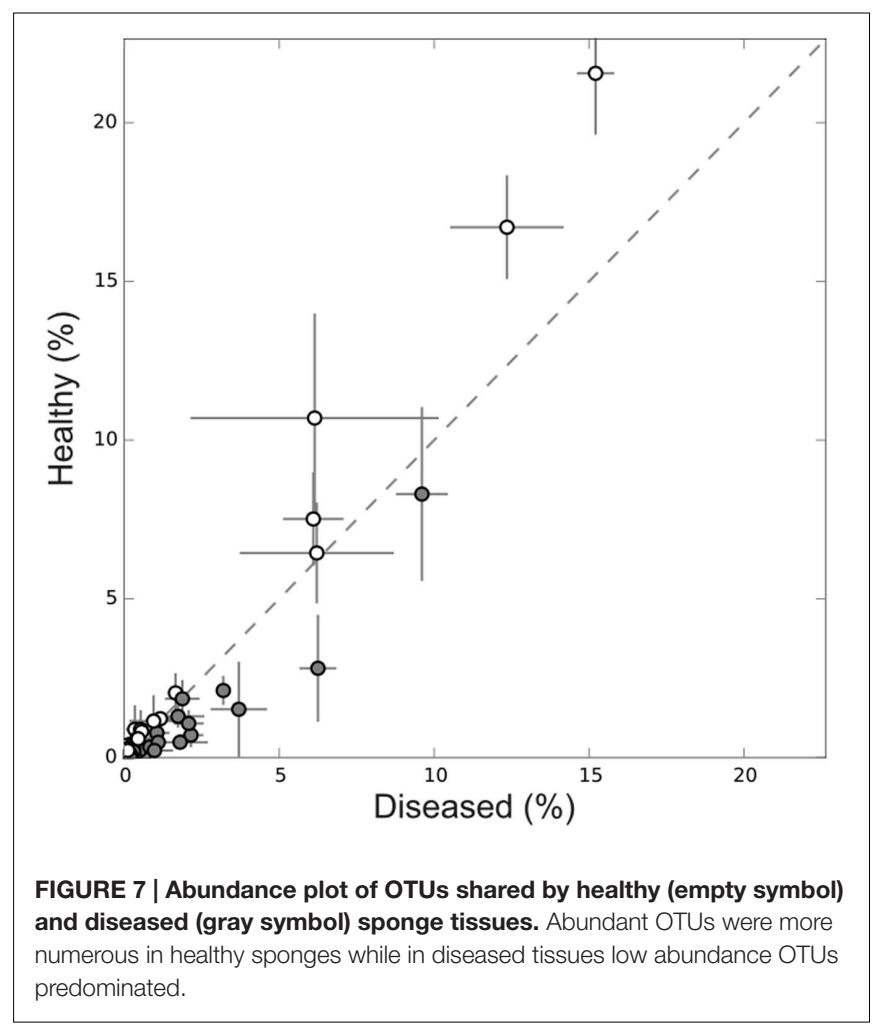

\section{DISCUSSION}

Our study targeting healthy and early diseased individuals of I. Fasciculata revealed an alteration of the sponge bacterial community during the first phase of a Mediterranean massive sponge die-off caused by anomalous high temperatures (Cebrian et al., 2011). We hypothesize that the temperature-produced stress, to which the sponges were subjected, unbalanced the symbiotic bacterial community of healthy sponges causing changes in the sponge bacterial community composition and diversity. Seawater warming above normal values produces physiological stress in sponges (López-Legentil et al., 2008), which requires protein repair at the expenses of other vital functions (Agell et al., 2001). Stress has been reported to lower the sponge resistance against pathogens (Saby et al., 2009) and has been associated to infections (e.g., Klein, 1993). Thus, sponge stress likely caused the first bacterial community changes observed in early diseased sponges before opportunistic pathogens may operate. However, resistance to high temperatures and responses to consequent stress may be species-specific, as sublethal thermal stress did not produce a microbiome shift in the sponge $R$. odorabile until tissue necrosis was initiated (Simister et al., 2012).

One diseased sample differed from the other two with a lower number of Verrucomicrobia OTUs and the presence of Nitrospira, which could suggest that it represented a different stage of the disease, or simply variability in the samples. Conversely, an increase in Verrucomicrobia representatives has been recorded in diseased Crella cyatophora sponges from the Reed Sea (Gao et al., 2015), although, this enrichment might be due to the algae assemblages that covered the diseased sponge tissues (Gao et al., 2015).

At high taxonomical levels, the most abundant phyla in healthy I. fasciculata decreased in abundance in diseased tissues. Diseased samples showed less Deltaproteobacteria and more Gammaproteobacteria and Acidobacteria OTUs than healthy tissues. Shifts in sponge-associated bacteria community composition have been reported for other diseased sponges (reviewed in Webster, 2007; Gao et al., 2014, 2015), though changes seem to vary according to the sponge species and maybe the disease phase. Diseased individuals of $A$. aerophoba and $R$. odorabile showed higher abundances of Bacteroidetes, Deltaproteobacteria, and Firmicutes, and lower abundances of Cyanobacteria, Chloroflexi, and Alpha-and Gammaproteobacteria (Webster et al., 2008), a pattern shared by some corals (Cooney et al., 2002; Frias-Lopez et al., 2002).

Most of the OTUs exclusively retrieved from diseased tissues of I. fasciculata have been reported from other sponges, in particular of the genus Ircinia. Some OTUs were shared with cultured Ircinia strobilina and Mycale laxissima from the Caribbean (Mohamed et al., 2008a,b). Thus, phylogenetically close bacterial OTUs are present in healthy sponges from other geographical areas.

We observed higher bacterial diversity in diseased tissues. Increases in community diversity have also been recorded during sponge diseases in other oceans (Webster et al., 2008; Angermeier et al., 2011; but see Luter et al., 2010) and in cultured sponges (Mohamed et al., 2008a,b). Weakness of the sponge immunity system in stressed sponges, either because of culture conditions or anomalous high temperatures, combined with the appearance of new niches during protein degradation, may allow the presence of additional (not strictly symbiotic) bacteria, fostering bacterial diversity in unhealthy sponges. 
Particular pathogens have been related to advanced stages of sponge diseases (Choudhury et al., 2015). A virus was reported to invade the diseased tissues of the sponge Aplysina cavernicola (Vacelet and Gallissian, 1978). Stabili et al. (2012) suggested that $V$. rotiferianus was involved in mortalities of Ircinia spp. from the South Adriatic and the Ionian Sea because it was isolated on agar plates from diseased sponge fragments, though its presence in the sponge tissues could not be confirmed. In our study, we detected only few sequences of one Vibrio OTU in both seawater and diseased tissue. Although, Vibrio spp. had been previously reported from other diseased sponges (Negandhi et al., 2010) and corals (e.g., Ben-Haim et al., 2003; Sussman et al., 2008), our results cannot demonstrate its direct implication in the mortality episodes of I. fasciculata as no significant increases in Vibrio sequences were detected in diseased tissues.

A decline in Cyanobacteria abundance was proposed to trigger the disease (Cebrian et al., 2011), which is likely since the absence of the Cyanobacteria colored layer was the most evident external symptom of the disease. However, it cannot be confirmed with our data as we removed on purpose the external Cyanobacteria-rich layer of the sponges to avoid our sequencing to be flooded by a single cyanobacterial OTU (see methods). Cyanobacteria are key components of the I. fasciculata microbiome (Erwin et al., 2012c) and may cover, as it has been reported for Ircinia sponges from other latitudes, a significant part of the species metabolic needs (Wilkinson, 1983). Thus, the sponge survival may be seriously compromised after Cyanobacteria decay in diseased tissues, leaving room for other components of the sponge microbiome to proliferate. Despites the absence of the external cyanobacterial layer, a total of 23 Cyanobacteria OTUs were retrieved from the inner part of the sponge and were significantly more abundant in healthy tissues. A Cyanobacteria shift was recorded earlier

\section{REFERENCES}

Agell, G., Uriz, M. J., Cebrian, G., and Martí, R. (2001). Does stress protein induction by copper modify natural toxicity in sponges. Environ. Toxicol. Chem. 20, 2588-2593. doi: 10.1002/etc.5620201126

Altschul, S. F., Gish, W., Miller, W., Myers, E. W., and Lipman, D. J. (1990). Basic local alignment search tool. J. Mol. Biol. 215, 403-410. doi: 10.1016/S00222836(05)80360-2

Angermeier, H., Glockner, V., Pawlik, J. R., Lindquist, N. L., and Hentschel, U. (2012). Sponge white patch disease affecting the Caribbean sponge Amphimedon compressa. Dis. Aquat. Organ. 99, 95-102. doi: 10.3354/dao 02460

Angermeier, H., Kamke, J., Abdelmohsen, U. R., Krohne, G., Pawlik, J. R., Lindquist, N. L., et al. (2011). The pathology of sponge orange band disease affecting the Caribbean barrel sponge Xestospongia muta. FEMS Microbiol. Ecol. 75, 218-230. doi: 10.1111/j.1574-6941.2010. 01001.x

Ben-Haim, Y., Thompson, F. L., Thompson, C. C., Cnockaert, M. C., Hoste, B., Swings, J., et al. (2003). Vibrio coralliilyticus sp. nov., a temperature-dependent pathogen of the coral Pocillopora damicornis. Int. J. Syst. Evol. Microbiol. 53, 309-315. doi: 10.1099/ijs.0.02402-0

Blanquer, A., Uriz, M. J., and Galand, P. (2013). Removing enviromental sources of variation to gain insight on symbionts vs transient microbes in high and low microbial abundance sponges. Environ. Microbiol. 15, 3008-3019. doi: $10.1111 / 1462-2920.12261$ in the sponge Xestospongia muta, with healthy individuals mainly harboring Synechococcus/Prochlorococcus and orangeband-diseased individuals containing other Cyanobacteria previously associated with coral diseases, seawater, and sediments (Angermeier et al., 2011, 2012).

To summarize, as in previous studies of sponge diseases (Webster et al., 2008; Sweet et al., 2015), but in contrast to the unambiguous identification of a sponge pathogen in diseased $R$. odorabile from the Indo-Pacific (Choudhury et al., 2015), our study does not support the hypothesis of a sole pathogen, whether a Vibrio or any other bacteria, as the triggering factor of the Northwestern Mediterranean mass mortalities of I. fasciculata. Our results suggest a scenario where the bacterial community balance is disrupted in healthy sponges by a shift in the relative bacterial OTUs abundances and the consequent decrease of the sponge fitness, with later invasion of sponge-coral-specific opportunistic bacteria and purported pathogens.

\section{AUTHOR CONTRIBUTIONS}

All authors listed, have made substantial, direct and intellectual contribution to the work, and approved it for publication.

\section{ACKNOWLEDGMENTS}

This study has partially been funded by projects MarSymbiOmics (MINECO, I+D+I of Excellence, CTM2013-43287-P), the Benthic Ecology Consolidate Team 2014-SGR-120 (Generalitat de Catalunya), and BluePharm Train FP7 People-INT, to MU The work of PG was supported by the Agence Nationale de la Recherche (ANR) through the projects EUREKA (ANR-14CE02-0004-01).

Bourne, D., Iida, Y., Uthicke, S., and Smith-Keune, C. (2008). Changes in coralassociated microbial communities during a bleaching event. ISME J. 2, 350-363. doi: $10.1038 /$ ismej.2007.112

Cebrian, E., Uriz, M. J., Garrabou, E., and Ballesteros, E. (2011). Sponge mass mortalities in a warming Mediterranean. Are Cyanobacteria-harboring species worse off? PLoS ONE 6:e20211. doi: 10.1371/journal.pone.0020211

Cerrano, C., Bavestrello, G., Bianchi, C. N., Cattaneo-vietti, R., Bava, S., Morganti, C., et al. (2000). A catastrophicmass-mortality episode of gorgonians and other organisms inhe Ligurian Sea (North-Western Mediterranean), summer 1999. Ecol. Lett. 3, 284-293. doi: 10.1046/j.1461-0248.2000.00152.x

Cervino, J. M., Winiarski-Cervino, K., Polson, S. W., Goreau, T., and Smith, G. W. (2006). Identification of bacteria associated with a disease affecting the marine sponge Ianthella basta in New Britain, Papua New Guinea. Mar. Ecol. Prog. Ser. 324, 139-150. doi: 10.3354/meps324139

Choudhury, J. D., Pramanik, A., Webster, N. S., Llewellyn, L. E., Gachhui, R., and Mukherjee, J. (2015). The pathogen of the great barrier reef sponge rhopaloeidesodorabileis a new strain of Pseudoalteromonas agarivorans containing abundant and diverse virulence-related genes. Mar. Biotechnol. 17, 463-478. doi: 10.1007/s10126-015-9627-y

Clarke, K. R., Somerfield, P. J., and Chapman, M. G. (2006). On resemblance measures for ecological studies, including taxonomic dissimilarities and a zeroadjusted Bray-Curtis coefficient for denuded assemblages. J. Exp. Mar. Biol. Ecol. 330, 55-80. doi: 10.1016/j.jembe.2005.12.017

Coma, R., Linares, C., Ribes, M., Diaz, D., Garrabou, J., and Ballesteros, E. (2006). Consequencesof a mass mortality in populations of Eunicella singularis 
(Cnidaria: Octocorallia) inMenorca (NW Mediterranean). Mar. Ecol. Prog. Ser. 327, 51-60. doi: 10.3354/meps327051

Cooney, R., Pantos, O., Le Tissler, M., Barer, M., O’Donnell, A., and Bythell, J. (2002). Characterization of the bacterial consortium associated with black band disease in coral using molecular microbiological techniques. Environ. Microbiol. 4, 401-413. doi: 10.1046/j.1462-2920.2002.00308.x

DeSantis, T. Z., Hugenholtz, P., Larsen, N., Rojas, M., Brodie, E. L., Keller, K., et al. (2006). Greengenes, a chimerachecked16S rRNA gene database and workbench compatible with ARB. Appl. Environ. Microbiol. 72, 5069-5072. doi: 10.1128/AEM.03006-05

Di Camillo, C. G., Bartolucci, I., Cerrano, C., and Bavestrello, H. (2013), Sponge disease in the Adriatic sea. Mar. Ecol. 34, 62-71. doi: 10.1111/j.14390485.2012.00525.x

Edgar, R. C. (2004). MUSCLE: multiple sequence alignmentwith high accuracy and high throughput. Nucleic Acids Res. 32, 1792-1797. doi: 10.1093/nar/gkh340

Edgar, R. C. (2010). Search and clustering orders of magnitudefaster than BLAST. Bioinformatics 26, 2460-2461. doi: 10.1093/bioinformatics/btq461

Erwin, P., López-Legentil, S., González-Pech, R., and Turon, T. (2012a). A specific mix of generalists: bacterial symbionts in Mediterranean Ircinia spp. FEMS Microbiol. Ecol. 79, 619-637. doi: 10.1111/j.1574-6941.2011.01243.x

Erwin, P., López-Legentil, S., and Turon, X. (2012c). Ultrastructure, molecular phylogenetics and chlorophyll a content of novelcyanobacterial symbionts in temperate sponges. Microbiol. Ecol. 64, 771-783. doi: 10.1007/s00248-0120047-5

Erwin, P., Pita, L., López-Legentil, S., and Turon, X. (2012b). Stability of spongeassociated bacteria over large seasonal shifts in temperature and irradiance. Appl. Environ. Microbiol. 78, 7358-7368. doi: 10.1128/AEM.02035-12

Felsenstein, J. (1989). PHYLIP - phylogeny inference package (Version 3.2). Cladistics 5, 164-166.

Frias-Lopez, J., Zerkle, A. L., Bonheyo, G. T., and Fouke, B. W. (2002). Partitioning of bacterial communities between seawater and healthy, black band diseased, and dead coral surfaces. Appl. Environ. Microbiol. 68, 2214-2228. doi: 10.1128/AEM.68.5.2214-2228.2002

Gaino, E., and Pronzato, R. (1989). Ultrastructure evidence of bacterial damage to Spongia oficinalis fibres (Porifera, Demospongiae). Dis. Aquat. Org. 6, 67-74. doi: $10.3354 /$ dao006067

Gao, Z. M., Wang, Y., Lee, O. O., Tian, R. M., Wong, Y. H., Bougouff, S., et al. (2014). Pyrosequencing reveals the microbial communities in the red seasponge Carteriospongia foliascens and their impressive shifts in abnormal tissues. Microb. Ecol. 68, 621-632. doi: 10.1007/s00248-014-0419-0

Gao, Z. M., Wang, Y., Tian, R. M., Lee, O. O., Wong, Y. H., Batang, Z. B., et al. (2015). Pyrosequencing revealed shifts of prokaryotic communities between healthy and disease-like tissues of the Red Sea sponge Crella cyathophora. PeerJ 3:e890. doi: 10.7717/peerj.890

Garrabou, J., Coma, R., Bensoussan, N., Bally, M., Chevaldonné, P., Cigliano, M., et al. (2009). Mass mortality in Northwestern Mediterranean rocky benthic communities: effects of the 2003 heat wave. Glob. Chang. Biol. 15, 1090-1103. doi: $10.1111 / j .1365-2486.2008 .01823 . x$

Gilbert, J. A., Field, D., Swift, P., Newbold, L., Oliver, A., Smyth, T., et al. (2009). The seasonal structure of microbialcommunities in the Western English Channel. Environ. Microbiol. 11, 3132-3139. doi: 10.1111/j.1462-2920.2009.02017.x

Hammer, Ø., Harper, D. A. T., and Ryan, P. D. (2001). PAST: paleontological statistics software package for education and data analysis. Palaeo Electron. $4,99$.

Harvell, C. D., Mitchell, C. E., Ward, J. R., Altizer, S., Dobson, A. P., Ostfeld, R. S., et al. (2002). Climate warming and disease risks for terrestrial and marine biota. Science 296, 2158-2162. doi: 10.1126/science.1063699

Huse, S., Welch, D. M., Morrison, H., and Sogin, M. L. (2010). Ironing out the wrinkles in the rare biospherethrough improved OTU clustering. Environ. Microbiol. 12, 1889-1898. doi: 10.1111/j.1462-2920.2010.02193.x

Klein, T. W. (1993). Stress and infections. J. Fla Med. Assoc. 80, 409-401.

Koukouras, A., Russo, A., Voultsiadou-Koukoura, E., Dounas, C., and Chintiroglou, C. (1992). Relationship of sponge macrofauna with the morphology of their hosts in the North Aegean Sea. Int. Rev. Hydrobiol. 77, 609-619. doi: 10.1002/iroh.19920770406

Koukouras, A., Voultsiadou-Koukoura, E., Chintiroglou, H., and Dounas, C. (1985). A comparison of the macrobenthic animal assemblages associated with seven sponge species. Cahiers de Biol. Mar. 26, 301-319.
Kunin, V., Engelbrektson, A., Ochman, H., and Hugenholtz, P. (2010). Wrinkles in the rare biosphere: pyrosequencingerrors can lead to artificial inflation of diversity estimates. Environ. Microbiol. 12, 118-123. doi: 10.1111/j.14622920.2009.02051.x

Kunin, V., and Hugenholtz, B. (2010). PyroTagger: a fast, accurate pipeline for analysis of rRNA ampliconpyrosequence data. Open J. 1, 1-8.

Lemoine, N., Buell, N., Hill, A., and Hill, M. (2007). "Assessing the utility of sponge microbial symbiont communities as models to study global climate change: a case study with Halichondria bowerbanki," in Porifera Research: Biodiversity, Innovation and Sustainability. Custódio, M.R., Lôbo-Hajdu, G., Hajdu, E., and Muricy, G., ed. R. de Janeiro (Rio de Janeiro: Museu Nacional), 419-425.

Lesser, M. P., Bythell, J. C., Gates, R. D., Johnstone, R. W., and Hoegh-Guldberg, O. (2007). Are infectious diseases really killing corals? Alternative interpretations of the experimental and ecologicaldata. J. Exp. Mar. Biol. Ecol. 346, 36-44. doi: 10.1016/j.jembe.2007.02.015

López-Legentil, S., Erwin, P. E., Pawlik, J. R., and Song, B. (2010). Effects of sponge bleaching on ammonia-oxidizing Archaea: distribution and relative expression of ammonia monoxygenase genes associated with the giant barrel sponge Xestospongia muta. Mol. Ecol. 60, 561-571. doi: 10.1007/s00248-010-9662-1

López-Legentil, S., Song, B., McMurray, S. E., and Pawlik, J. R. (2008). Bleaching and stress in coral reef ecosystems: hsp70 expression by the giant barrel sponge Xestospongia muta. Mol. Ecol. 17, 1840-1849. doi: 10.1111/j.1365294X.2008.03667.x

Luter, H. M., Whalan, S., and Webster, N. S. (2010). Exploring the role of microorganisms in the disease-like syndrome affecting the sponge Ianthella basta. Appl. Environ. Microbiol. 76, 5736-5744. doi: 10.1128/AEM. 00653-10

Maldonado, M., Sánchez-Tocino, L., and Navarro, C. (2010). Recurrent diseaseoutbreaks in corneous demosponges of the genus Ircinia: epidemicincidence and defense mechanisms. Mar. Biol. 157, 1577-1590. doi: 10.1007/s00227-010-1431-7

Mohamed, N. M., Enticknap, J. J., Lohr, J. E., McIntosh, S. M., and Hill, R. T. (2008a). Changes in bacterial communities of the marine sponge Mycale laxissima on transfer into aquaculture. Appl. Environ. Microbiol. 74, 1209-1222. doi: 10.1128/AEM.00454-08

Mohamed, N. M., Rao, V., Hamann, M. T., and Hill, R. T. (2008b). Monitoring bacterial diversity of the marine sponge Ircinia strobilina upon transfer into aquaculture. Appl. Environ. Microbiol. 74, 4133-4143. doi: 10.1128/AEM.00454-08

Montalvo, N. F., and Hill, R. T. (2011). Sponge-associated bacteriaare strictly maintained in two closely related but geographicallydistant sponge hosts. Appl. Environ. Microbiol. 77, 7207-7216. doi: 10.1128/AEM.05285-11

Negandhi, K., Blackwelder, P. L., Ereskosky, A. V., and Lopez, J. V. (2010). Florida reedsponges harbor coral-disease associated microbes. Symbiosis 51, 117-129. doi: 10.1007/s13199-010-0059-1

Olson, J. B., Gochfeld, D. J., and Slattery, M. (2006). Aplysina red band syndrome: a new threat to Caribbean sponges. Dis. Aquat. Organ. 71, 163-168. doi: 10.3354/dao071163

Olson, J. B., Thacker, R. W., and Gochfeld, D. J. (2014). Molecular community profilingreveals impacts of time, space, and disease status on the bacterialcommunity associated with the Caribbean sponge Aplysinacauliformis. FEMS Microbiol. Ecol. 87, 268-279. doi: 10.1111/1574-6941.12222

Parks, D. H., Tyson, G. W., Hugenholtz, P., and Beiko, R. G. (2014). STAMP: statistical analysis of taxonomic and functional profiles. Bioinformatics 30 , 3123-3124. doi: 10.1093/bioinformatics/btu494

Perez, T., Garrabou, J., Sartoretto, S., Harmelin, J. G., Francour, P., and Vacelet, J. (2000). Mortalité massive d'invertébrés marins: un événement sans précédent en Méditerranée nord-occidentale. C. R. Acad. Sci. 323, 853-865. doi: 10.1016/S0764-4469(00)01237-3

Pinnegar, J. K., Polunin, N. V. C., Francour, P., Badalamenti, F., Chemell, O., Harmelin-vivien, L., et al. (2000). Trophic cascades in benthic marine ecosystems: lessons for fisheries and protected-area management. Environ. Conserv. 27, 179-200. doi: 10.1017/S0376892900000205

Pita, L., Erwin, P. M., Turon, X., and López-Legentil, S. (2013a). Till death do us part: stable sponge-bacteria associations under thermal and food shortagestresses. PLoS ONE 8:e80307. doi: 10.1371/journal.pone.0080307 
Pita, L., Turon, X., López-Legentil, S., and Erwin, P. (2013b). Host rules: spatial stability of bacterial communities associated with marine sponges (Ircinia spp.) in the Western Mediterranean Sea. FEMS Microbiol. Ecol. 86, 268-276. doi: 10.1111/1574-6941.12159

Rosenberg, E., and Ben-Haim, Y. (2002). Microbial diseases of corals and global warming. Environ. Microbiol. 4, 318-326. doi: 10.1046/j.1462-2920.2002.00302.x

Rosenberg, E., Kushmaro, A., Kramarsky-Winter, E., Banin, E., and Yoss, L. (2009). The role of microorganisms in coral bleaching. ISME J. 2, 139-146. doi: 10.1038/ismej.2008.104

Rützler, K. (1988). Mangrove sponge disease induced by cyanobacterialsymbionts: failure of a primitive immune system? Dis. Aquat. Organ. 5, 143-149. doi: 10.3354/dao005143

Saby, E., Justesen, J., Kelve, M., and Uriz, M. J. (2009). In vitro effects of metal pollution on Mediterranean sponges: species-specific inhibition of 2_,5_-oligoadenylate synthetase. Aquat. Toxicol. 94, 204-210. doi: 10.1016/j.aquatox.2009.07.002

Schippers, K. J., Sipkema, D., Osinga, R., Smidt, H., Pomponi, S. A., Martens, D. E., et al. (2012). Cultivation of sponges, sponge cells and symbionts: achievements and future prospects- In : becerro MA, Uriz MJ, Maldonado M, Turon X (eds). Advances in sponge science: physiology, chemical and microbial diversity, biotechnology. Adv. Mar. Biol. 62, 273-337. doi: 10.1016/B978-0-12-3942838.00006-0

Simister, R., Taylor, M. W., Tsai, P., Fan, L., Bruxner, T. J., Crowe, M. L., et al. (2012). Thermal stress responses in the bacterial biosphere of the Great Barrier Reef sponge, Rhopaloeides odorabile. Environ. Microbiol. 14, 3232-3246. doi: $10.1111 / 1462-2920.12010$

Smith, F. G. W. (1941). Sponge disease in British Honduras, and its transmission by water currents. Ecology 22, 415-421. doi: 10.2307/1930719

Stabili, L., Cardone, F., Alifano, P., Tredici, S. M., Piraino, P., Corriero, G., et al. (2012). Epidemic mortality of the sponge Ircinia variabilis Schmidt (1862) associated to proliferation of a Vibrio bacteria. Microbiol. Ecol. 64, 802-813. doi: 10.1007/s00248-012-0068-0

Sussman, M., Willis, B. L., Victor, S., and Bourne, D. G. (2008). Coral pathogens identified for white syndrome (WS) epizootics in the Indo-Pacific. PLoS ONE 3:e2393. doi: 10.1371/journal.pone.0002393

Sutherland, K. P., Porter, J. W., and Torres, C. (2004). Disease and inmunity in Caribbean and Indo-Pacific zooxanthellate corals. Mar. Ecol. Prog. Ser. 266, 273-302. doi: 10.3354/meps266273
Sweet, M., Bulling, M., and Cerrano, C. (2015). A novel sponge disease caused by a consortium of micro-organisms. Coral Reefs 34, 871-883. doi: 10.1007/s00338015-1284-0

Turon, X., Garriga, A., and Erwin, P. M. (2013). Lights and shadows: growth patterns in three sympatric and congeneric sponges (Ircinia spp) with contrasting abundances of photosymbionts. Mar. Biol. 160, 2743-2754. doi: 10.1007/s00227-013-2267-8

Vacelet, J., and Gallissian, M. F. (1978). Virus-like particles in cells ofthe sponge Verongia cavernicola (Demospongiae, Dictyoceratida) and accompanying tissue changes. J. Invertebr. Pathol. 31, 246-254. doi: 10.1016/0022-2011(78)90014-9

Vacelet, J., Vacelet, E., Gaino, E., and Gallissian, M. F. (1994). "Bacterial attack of spongin skeleton during the 1986-1990 Mediterraneansponge disease," in Sponges in Time and Space, eds R. W. M. van Soest, T. M. G. van Kempen, and J. C. Braekman (Rotterdam: A.A. Balkema), 355-362.

Webster, N. S. (2007). Sponge disease: a global threat? Environ. Microbiol. 9, 1363-1375. doi: 10.1111/j.1462-2920.2007.01303.x

Webster, N. S., Negri, A. P., Webb, R. I., Russell, T., and Hill, R. T. (2002). A spongin-boring $\alpha$-proteobacterium is the etiological agent of disease in the great barrier reef sponge Rhopaloeides odorabile. Mar. Ecol. Prog. Ser. 232, 305-309. doi: 10.3354/meps232305

Webster, N. S., Xavier, J. R., Freckelton, M., Motti, C. A., and Cobb, R. (2008). Shifts inmicrobial and chemical patterns within the marine sponge Aplysina aerophoba during a disease outbreak. Environ. Microbiol. 10, 3366-3376. doi: 10.1111/j.1462-2920.2008.01734.x

Wilkinson, C. R. (1983). Net primary productivity in coral reef sponges. Science 219, 410-412. doi: 10.1126/science. 219.4583 .410

Conflict of Interest Statement: The authors declare that the research was conducted in the absence of any commercial or financial relationships that could be construed as a potential conflict of interest.

Copyright (c) 2016 Blanquer, Uriz, Cebrian and Galand. This is an open-access article distributed under the terms of the Creative Commons Attribution License (CC BY). The use, distribution or reproduction in other forums is permitted, provided the original author(s) or licensor are credited and that the original publication in this journal is cited, in accordance with accepted academic practice. No use, distribution or reproduction is permitted which does not comply with these terms. 